7. Reprod. Fert. (1966) 11, 299-301

BRIEF COMMUNICATION

\title{
THE CONSTRUCTION OF RECTAL ELECTRODES FOR ELECTRO-EJACULATION
}

\author{
P. HEALEY AND R. M. F. S. SADLEIR \\ Wellcome Institute of Comparative Physiology, Zoological Society of London, \\ Regent's Park, London
}

(Received 11th November 1965)

The technique of electro-ejaculation is now commonly used for the collection of semen from some domesticated species and is currently being applied in this Institute to exotic species of differing sizes. This note describes the construction of several types of rectal electrodes which we are using in the development of semen collection techniques. Originally a single rectal pole in combination with a needle pole inserted in the lumbar muscles was used by Gunn (1936) for electro-ejaculation of the ram. Laplaud \& Cassou (1945) did not describe the bipolar rectal electrode which they used on rams but later Thibault, Laplaud \& Ortavant (1948) gave details of a multipolar electrode having thirty brass rings, separated by vulcanite rings, for use on bulls. Blackshaw (1954) described a four-electrode pole for rams made from copper tubing covered with rubber on which brass rings were clamped and soldered. Marsden (1954) used multipolar ring electrodes on bulls, but obtained better results using a lucite pole with four longitudinal brass strips as electrodes.

The first method of constructing multi-ring electrodes was only used when electrodes less than $25 \mathrm{~mm}$ in diameter were required. Glass tubing was coated internally with silicone grease and into this was slipped a brass dome turned on a lathe (see Text-fig. 1) followed by a series of brass discs (each with three holes) which ultimately formed the electrical contacts with the rectum. Thick insulated copper wire (circa 14 gauge) was threaded through the central hole to support the discs at right angles to the tube. The second hole admitted wires which were soldered to each disc in turn. The glass tubing was then filled with Araldite in the proportions ten parts Epoxy resin-CY212, ten parts Hardener -HY 964 and one part Accelerator-DY064 (Ciba A.R.L. Ltd, Duxford, Cambs.). The third hole in the brass discs allowed air bubbles, trapped beneath each disc, to be gently tapped free and rise up through the column of liquid Araldite. The Araldite was then polymerized by suspending the glass tubing vertically in boiling water for 2 to $3 \mathrm{hr}$. After hardening, the glass mould was easily broken off leaving a solid rod with electrodes in place which was then smoothed with emery paper. Rectal electrodes A, B and G in Plate 1 were made by this technique. (The dimensions of electrodes $A$ to $F$ are given in Table 1.)

For the second method of construction, polythene rod was turned to the external diameter required. The diameter was further reduced by another $6 \mathrm{~mm}$ 299 
anteriorly from the required position of the most posterior ring (see Text-fig. 1). A channel $5 \times 5 \mathrm{~mm}$ in depth was milled longitudinally along the rod. A turned brass ring, $3 \mathrm{~mm}$ thick and of the same external diameter as the thicker section of the rod, was then slipped along the shaft and fitted snugly against the shoulder. Wire was soldered to the ring and laid in the channel. A turned Perspex (I.C.I.) cylinder $3 \mathrm{~mm}$ thick and fitting snugly on the polythene shaft was then slipped along the shaft until it rested against the brass ring. The sequence of ring then cylinder was continued anteriorly with the wires fed posteriorly along the channel. A turned brass dome with a threaded undercut

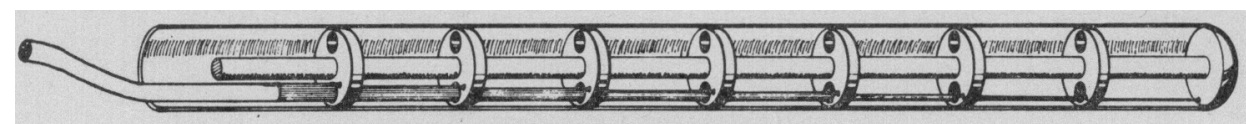

(a)

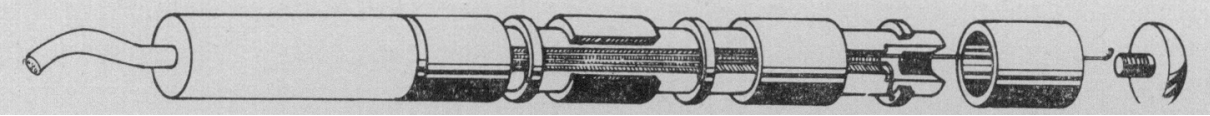

(b)

TEXT-FIG. 1. Expanded drawing of the structure of multi-ring rectal electrodes made by the first (a) and second (b) methods.

TABLE 1

DiMENSIONS (mm) OF REGTAL ELECTRODES SHOWN IN PLATE 1

\begin{tabular}{c|c|c|c|c}
\hline & Length* & Diameter & Thickness of discs & Space between discs \\
\cline { 2 - 4 } & 205 & 21.5 & 3.0 & $24 \cdot 0$ \\
A & 60 & $16 \cdot 0$ & $5 \cdot 5$ & $8 \cdot 5$ \\
C & 130 & 10.5 & $3 \cdot 2$ & $19 \cdot 5$ \\
D & 155 & $37 \cdot 0$ & $3 \cdot 2$ & $26 \cdot 0$ \\
E & 200 & $49 \cdot 0$ & 5.5 & $31 \cdot 0$ \\
F & 150 & 39.0 & - & - \\
\hline
\end{tabular}

* From anterior end of shaft to posterior ring or posterior end of strip.

was screwed into the end of the polythene rod to lock the rings and cylinders in place. Finally, the channel posterior to the last ring was filled with melted polythene with the wires in place and the whole electrode smoothed with emery paper. We have found this method of construction is not very successful because the Perspex cylinders tend to crack easily. If polythene cylinders are used it is difficult to seat them snugly against the brass rings and they tend to bow out and flare over the rings when the terminal dome is screwed up tight. Rectal electrode D (Plate 1) was constructed by this method.

Electrodes of large diameter (over $50 \mathrm{~mm}$ ) were constructed by first turning polythene rod to the necessary external diameter. Circular grooves were turned at the ring positions and a longitudinal channel milled for the wires. Brass rings were turned to fit the grooves with their surfaces flush with the rod. 


\section{PLATE 1}

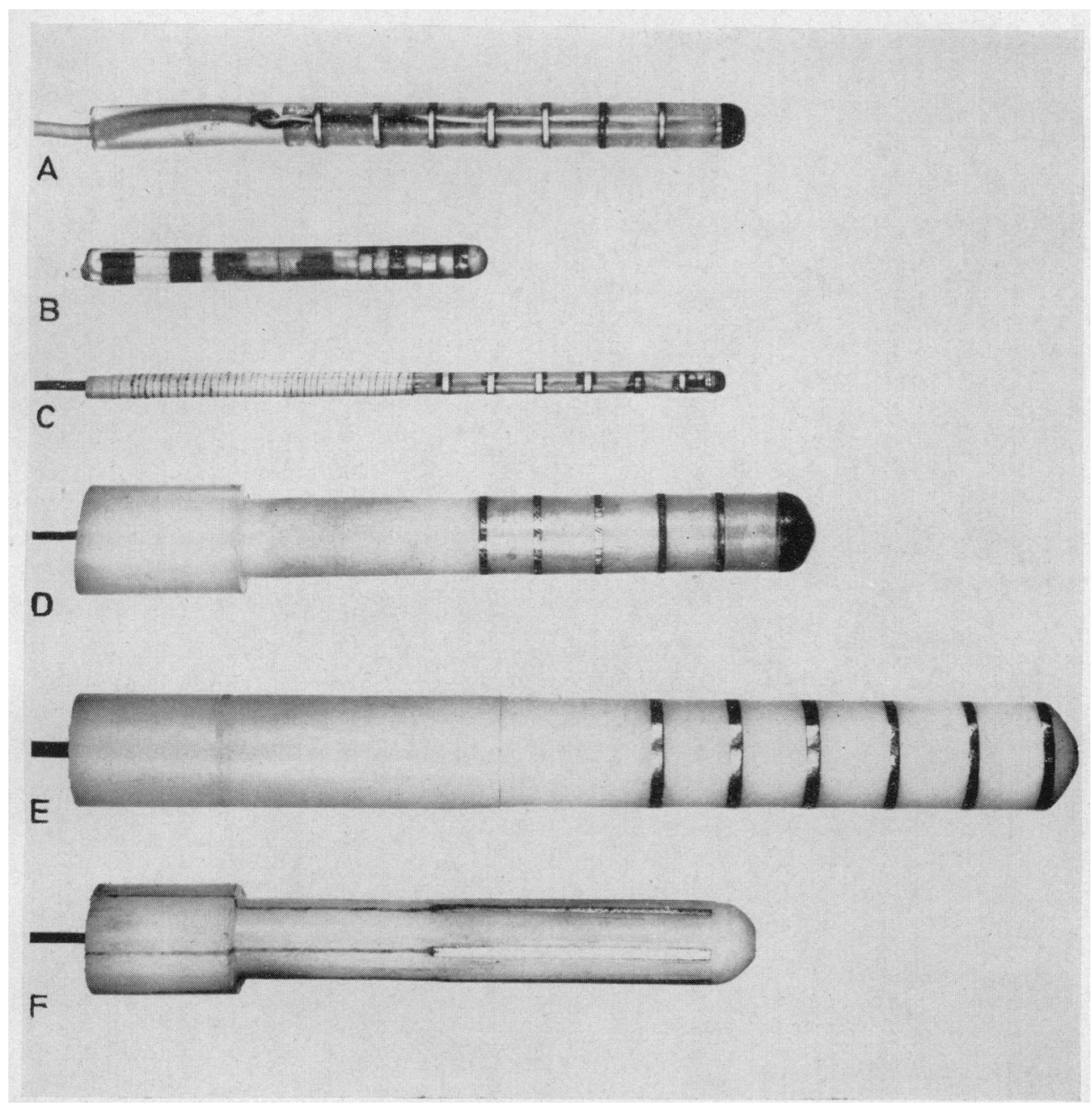

Rectal electrodes. Dimensions are given in Table 1.

(Facing p. 300) 
They are then split, opened slightly, and holes drilled about $30 \mathrm{~mm}$ on either side of the split. The rings were then clamped into the circular groove and pins driven through the holes into the polythene. Wires were then fed down the longitudinal groove and joined to the solder used to fill the split portion of the ring. The groove was then filled with molten polythene and the surface of the electrode smoothed as before. We have found this method unsatisfactory for small diameter electrodes because if the rings are opened out they do not return to an exactly circular shape and cannot easily be smoothed to the circumference of the shaft. Rectal electrode E (Plate 1) was made by this method.

For the construction of longitudinal strip electrodes, polythene rod was turned to the required diameter and a longitudinal hole bored up its centre from the handle (posterior) end. Six strips $125 \times 4 \times 3.5 \mathrm{~mm}$ were cut from brass sheet and three holes drilled in each. Pairs of strips were heated, placed on opposite sides of the shaft of the pole, and clamped in a vice to melt the polythene so that the strips could sink into the shaft. Pins were then driven through the holes to hold the strips firmly in place. Holes bored radially from the posterior end of the strips into the central hole were used to pass wires (soldered to the strips) along inside the handle. These holes were filled with molten polythene and the electrode was finally smoothed. Rectal pole F (Plate 1) was made by this method. A similar pole was made by milling grooves in Perspex rod, into which brass strips $92 \times 3 \times 3.5 \mathrm{~mm}$ were fitted and sealed with Araldite.

With the multi-ring electrodes it is possible to wire each alternate ring to two wires and thus have positive and negative poles alternating along the electrode. We have found that wiring each ring separately to multi-core cable gives greater flexibility. This cable is plugged into a variable connection junction box to facilitate the connecting and disconnecting and changing the polarity of each ring. If necessary, this operation can be made when the electrode is inside the rectum.

\section{REFERENCES}

Blackshaw, A. W. (1954) A bipolar rectal electrode for the electrical production of ejaculation in sheep. Aust. vet. 7. 30, 249.

Gunn, R. M. C. (1936) Fertility in sheep: Artificial production of seminal ejaculation and the characters of the spermatozoa contained therein. Bull. Commonw. Scient. ind. Res. Org. 94, 1.

Laplaud, M. \& Cassou, R. (1945) Nouveau procédé de récolte du sperm par électrode bipolaire rectal unique. C.r. hebd. Séanc. Acad. Agric. Fr. 31, 37.

Marsden, W. G. R. (1954) New advances in the electro-ejaculation of the bull. F. Dairy Sci. 37, 556.

Thibault, G., Laplaud, M. \& Ortavant, R. (1948) L'électro-éjaculation chez le Taureau. Technique et résultats. C.r. Séanc. Acad. Sci., Paris, 226, 2006. 